\title{
MECHANICAL BEHAVIOR OF DOWEL CONNECTION FOR TIMBER-CONCRETE COMPOSITE RURAL BRIDGES
}

\author{
André Filipe Silva Marques ${ }^{1, \star}$, Carlos Eduardo Jesus Martins ${ }^{1,2}$, Alfredo Manuel Pereira Geraldes Dias ${ }^{1,2}$
}

\begin{abstract}
This study focuses on the evaluation of the mechanical behavior of two types of connections for intended use in rural Timber-Concrete Composite traffic bridges. The two connection types used were the " $X$ " type connection - XD and the dowel type connection - PD. Firstly, static shear tests in small-scale specimens were performed in both connection types and higher results were obtained for the XD series, both for stiffness and load carrying capacity. Secondly, the PD connection was chosen, based on practical and economical aspects, for further testing also in small-scale specimens, including cyclic tests. The influence of the number of cycles in the connection stiffness and load carrying capacity was evaluated. It was concluded that the load carrying capacity increased after the application of a pre-defined number of load cycles and that the connection stiffness increased $80,6 \%$ and $34,1 \%$ after 10000 and 1000 cycles, respectively, for different applied load levels. Also the increase of load level in the cyclic tests affected the performance of the connection, leading to a decrease in stiffness.
\end{abstract}

Keywords: Bridges, composite structures, dowel connection, timber-concrete, timber structures, TCC connections.

\section{INTRODUCTION}

In Timber-Concrete Composite (TCC) structures timber and concrete are combined in such a way that their mechanical properties are used to the greatest advantage of the system. The development of this composite solution was driven by the shortage of steel for construction after the two World Wars, however, in the last 50 years, TCC systems become increasingly used in Europe, initially in the refurbishment of old timber floors and afterwards in the construction of new buildings (Dias et al. 2016). Later, TCC started to be used also in traffic bridges (Rodrigues et al. 2010, Rodrigues et al. 2013, Dias et al. 2016) where the TCC system usually consists in: i) slab bridges (timber layer with concrete slab on top), with the timber layer being usually composed by solid circular beams (logs) or sawn timber beams, or ii) girder bridges (T-beam decks), where the concrete slab is, most commonly, casted on top of equally spaced glulam beams (Rodrigues et al. 2013).

In rural and forest roads where, typically the traffic volume is low, and many small watercourses and trenches to overcome can be found, the construction of small span bridges ( 5 to 8 meters) using TCC decks with round wood elements can be an economic, quick and competitive solution because: i) besides the structural role, the timber slab is also used as lost formwork which leads to a substantial reduction in the use of additional formwork in deck construction; ii) the timber resources (logs) to be used are often locally available, which might permit a saving in transportation and iii) the use of round wood also reduces the processing costs.

A practical example can be found in Brazil where the use of the TCC system was mentioned as an adequate alternative not only for the retrofitting and reinforcement of the existent timber bridges, built in vicinal and

${ }^{1}$ SerQ - Centro de Inovação e Competências da Floresta, Sertã, Portugal.

${ }^{2}$ ISISE, Departamento de Engenharia Civil, Universidade de Coimbra, Rua Luís Reis Santos, Coimbra, Portugal.

•Corresponding author: amarques@serq.pt

Received: 10.12.2018 Accepted: 06.11.2019 
rural roads, but also for the construction of new TCC bridges. A real prototype was already built using logs from Eucalyptus citriodora together with an upper concrete slab (Calil et al. 2004, Soriano and Mascia 2009).

Despite the use of TCC in bridges, technical codes and regulations addressing this solution are limited. In the United States of America (USA), the AASHTO (American Association of State Highway and Transportation Officials), covered the most important issues and some additional aspects. Similar situation occurred in Canada with the Canadian Bridge Code (CSA 2016). In South America a manual for construction of timber bridges also provide important indications for the design of TCC bridges (Calil 2006). In Australia, the Timber Bridge Manual (RTA 2008) has a full section dedicated to TCC bridges including design, construction and maintenance. In Europe, the design of TCC bridges is briefly mentioned in the Eurocode 5, Part 2 (CEN 2004b).

One key aspect in the design of TCC solutions is the connection system between timber and concrete that must prevent the uplift and resist to the shear stresses in the timber-concrete interface, ensuring that slip levels do not endanger the composite action of the transversal section. Additionally, their use in bridges brings another important requirement, the fatigue performance. This aspect is stated in bridge load standards (CEN 2003) and fatigue verifications are given for road bridges, which should be included in the design. Regarding the timber elements, a brief mention of the fatigue strength is made in Eurocode 5, Part 2 (CEN 2004b). The $\mathrm{S}-\mathrm{N}$ line for the respective type of connection is usually determined through cyclic testing of shear specimens and/or TCC beams for fatigue verification on the connection.

Over time, many different connection systems were developed and tested for application in TCC structures, leading to different levels of composite action (Dias et al. 2015, Martins et al. 2016, Sebastian et al. 2017). However, for bridge application due to the higher structural requirements the configurations of the connection systems commonly used for floors are not suitable. Different connection systems and configurations suitable for bridge application have been developed showing quite different mechanical performance, nevertheless, the available studies and investigations regarding the fatigue performance of TCC connections are still scarce (Rodrigues et al. 2013).

Under the "Nordic Timber Bridge Project", a wide research focused on TCC bridges and more specifically in the shear connections, was developed. Emphasis was given to "glued X-bars" and "bent bars with notches" configurations that were subjected to static and dynamic shear tests in specimens kept in indoor and outdoor conditions (Mäkipuro et al. 1996). Both configurations are suitability to be used in TCC structures and the use of these connections was reported in Finnish bridges.

Still under the scope of the same project, different X-connector alternatives were tested through the application of cyclic loads (Tommola et al. 1999). No fatigue damages were found during the tests, however, the cyclic loading affected remarkably the stiffness of the connections.

The research developed by Döhrer and Rautenstrauch (2006) comprised: i) short-time shear tests, ii) longtime shear tests and iii) dynamic tests in TCC connections. Three types of connectors were used and it was concluded that all of the tested connectors are suitable for bridge application. Actually, one bridge (Birkberg-Bridge Wippra) was built using one of the connection system investigated in the study (Rautenstrauch et al. 2010).

For the determination of the S-N lines Aldi and Kuhlmann (2010) performed several fatigue tests in timber-concrete specimens and TCC-beams using grooved connection and crosswise glued-in rebars connection. The obtained S-N lines were compared with the rules from the codes and regulations and concluded that the use of the equation given in Eurocode 5 (CEN 2004b) could be considered a safe estimation for the prediction of the grooved connection. For crosswise glued-in rebars connection the indications of the Eurocode 2 (CEN 2004a) were used and similar conclusions were drawn.

Molina (2008) used logs of Eucalyptus citriodora in the TCC specimens fabricated for the characterization of two connection systems: i) perpendicular dowels and ii) X-type connection. Cyclic tests with different levels of applied loads were performed until all of the specimens, with one exception, reached 2 million load cycles, after which the specimens were tested to failure in static tests. It was concluded for both connection systems that the cyclic loading affected negatively the connection stiffness.

The present paper presents the work carried out in the development and testing of shear connectors for TCC bridges in rural environments, usin ground wood timber elements (logs) from Maritime Pine (Pinus pi- 
naster), due to the potential of the species (Marques et al. 2016, Martins et al. 2017), however, other species could be considered (Hermoso et al. 2015, Knapic et al. 2018, Gang Hu and Yuan Guan 2019).

In the first stage, specimens were fabricated with the two configurations for static shear tests, aiming the determination of load carrying capacity (maximum load) $\left(F_{\max }\right)$ and stiffness $\left(K_{s}\right)$. In the second stage, cyclic shear tests were performed in specimens with the connection system chosen considering economic and practical requirements, namely the cost of the connection and the speed and ease of execution. The objective was to understand the influence of the cyclic loading in the connection load carrying capacity and stiffness and also to determine the maximum number of load cycles until failure, for different levels of applied load.

\section{MATERIALS AND METHODS}

\section{Sample characterization}

The two connection systems considered in the present study were: i) the "X" type connection (XD) and ii) the dowel type connection (PD). The " $X$ " connection was used due to the good results reported by other authors for similar configurations. The dowel type connection, despite the usual lower values for the mechanical properties, was considered and used because of its economic and ease of execution.

In the XD configuration (Figure 1) two glued-in rebars, with $16 \mathrm{~mm}$ of diameter, were used as mechanical connectors in a crosswise orientation with an angle of $45^{\circ}$ relative to the longitudinal axis of the timber elements and no notches were considered. The connectors were inserted into the timber in $20 \mathrm{~mm}$ diameter predrilled holes and glued using a two component epoxy resin (SikaIcosit K101N). The total glued length inside the timber elements was about twelve times the diameter of the connector - $192 \mathrm{~mm}$.

The configuration of the PD connection (Figure 2) comprised two mechanical connectors materialized by two rebars with $16 \mathrm{~mm}$ diameter. The connectors were hammered perpendicularly to the log axis into $15 \mathrm{~mm}$ diameter pre-drilled holes and spaced $48 \mathrm{~mm}$ from each other. The total depth inside the timber elements was ten times the connector diameter $-160 \mathrm{~mm}$. The small-scale specimens were composed by a central round wood timber member together with two sided concrete members, forming two shear planes per specimen, with one connection per shear plane.

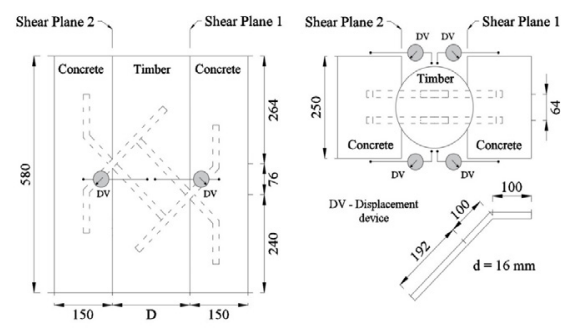

Figure 1: Specimens configuration with the XD connection.

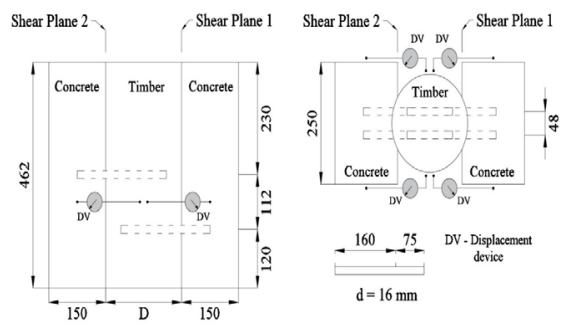

Figure 2: Specimens configuration with the PD configuration. 
Round wood timber elements from Portuguese Maritime Pine (Pinus pinaster) cut longitudinally with the desired length for each configuration were used. The mechanical connectors were obtained from A500 NR reinforcement steel bars with $500 \mathrm{MPa}$ of yield strength and the concrete used was C30/37 strength class (CEN 2004a). Table 1 summarizes the values of diameter and density of the timber elements used for specimens fabrication. For density determination, all timber pieces were measured and weighed.

Static tests were performed, firstly, in 27 specimens: 13 for the XD connection and 14 for the PD connection (PD1 series). Considering the results obtained, but especially practical aspects in the fabrication of the specimens, the PD connection was chosen for the second stage, reason that led to additional static tests in a set of 11 new fabricated specimens with the PD connection system (PD2 series). During the static tests of the first stage, it was observed that in all specimens, the concrete member failed at the connection horizontal level of shear plane 1. Therefore, to prevent this early failure, in the PD2 series specimens a reinforcement steel mesh was incorporated.

Table 1: Properties of the timber elements used in the fabrication of the specimens, XD and PD configurations.

\begin{tabular}{|c|c|c|c|c|}
\hline & \multicolumn{2}{|c|}{ XD connection } & \multicolumn{2}{c|}{ PD connection } \\
\hline & $\begin{array}{c}\text { Diameter } \\
(\mathbf{m m})\end{array}$ & $\begin{array}{c}\text { Density } \\
\left(\mathbf{k g} / \mathbf{m}^{\mathbf{3}}\right)\end{array}$ & $\begin{array}{c}\text { Diameter } \\
(\mathbf{m m})\end{array}$ & $\begin{array}{c}\text { Density } \\
\left(\mathbf{k g} / \mathbf{m}^{\mathbf{3}}\right)\end{array}$ \\
\hline Mean Value & 197,5 & 559,4 & 200,2 & 550,6 \\
\hline Maximum Value & 226,7 & 712,3 & 225,7 & 687,7 \\
\hline Minimum Value & 184,2 & 482,1 & 176,7 & 421,2 \\
\hline Coefficient of Variation (\%) & 6,4 & 11,7 & 6,1 & 11.0 \\
\hline Number of Tests & \multicolumn{2}{|c|}{13} & \multicolumn{2}{c}{45} \\
\hline
\end{tabular}

The second stage aimed primarily the characterization of the selected connection under cyclic loading - influence in the connection stiffness and load carrying capacity - and a total of 20 specimens were tested, according to the distribution shown Table 2. Also, the number of cycles to failure for different applied load levels was determined.

Table 2: Distribution of the specimens in the cyclic tests and indication of the number of cycles for which static tests were performed for the determination of intermediate values of the stiffness.

\begin{tabular}{|c|c|c|c|}
\hline $\begin{array}{l}\text { Number of } \\
\text { Specimens }\end{array}$ & $\begin{array}{l}\text { Maximum Load Level in } \\
\text { Cyclic Tests }\end{array}$ & $\begin{array}{c}\text { Pre-defined } \\
\text { number of } \\
\text { Cycles }\end{array}$ & $\begin{array}{c}\text { Number of cycles - } \\
\text { static tests for stiffness } \\
\text { evaluation }\end{array}$ \\
\hline \multirow{2}{*}{1} & \multirow{2}{*}{$30 \% F_{\text {est,cyc }}$} & \multirow{2}{*}{10000} & 0 \\
\hline & & & $10000+$ failure \\
\hline \multirow{5}{*}{2} & \multirow{5}{*}{$30 \% F_{e s t, c y c}$} & \multirow{5}{*}{100000} & 0 \\
\hline & & & 10000 \\
\hline & & & 30000 \\
\hline & & & 65000 \\
\hline & & & $100000+$ failure \\
\hline \multirow{3}{*}{2} & \multirow{3}{*}{$40 \% F_{e s t, c y c}$} & \multirow{3}{*}{1000} & 0 \\
\hline & & & 500 \\
\hline & & & $1000+$ failure \\
\hline \multirow{4}{*}{2} & \multirow{4}{*}{$40 \% F_{\text {est }, c y c}$} & \multirow{4}{*}{10000} & 0 \\
\hline & & & 1000 \\
\hline & & & 5000 \\
\hline & & & $10000+$ failure \\
\hline \multirow{8}{*}{2} & \multirow{8}{*}{$40 \% F_{\text {est,cyc }}$} & \multirow{8}{*}{100000} & 0 \\
\hline & & & 1000 \\
\hline & & & 5000 \\
\hline & & & 10000 \\
\hline & & & 20000 \\
\hline & & & 50000 \\
\hline & & & 80000 \\
\hline & & & $100000+$ failure \\
\hline 1 & $20 \% F_{\text {est,cyc }}$ & Until Failure & Still running \\
\hline 4 & $40 \% F_{\text {est,cyc }}$ & Until Failure & One static test per day \\
\hline 3 & $60 \% F_{\text {est, cyc }}$ & Until Failure & One static test per day \\
\hline 3 & $80 \% F_{\text {est }, c y c}$ & Until Failure & One static test per day \\
\hline
\end{tabular}




\section{Practical application}

In the present study, only small-scale specimens were used for the characterization of both connection systems, but the application in a full-size bridge is very similar. In the XD connection the pre-drilled holes in the timber are made with a $45^{\circ}$ angle with the longitudinal axis of the timber element, in a crosswise position, before application of the epoxy resin, after which the steel bars are placed carefully to avoid air bubbles inside the hole. The connectors should be held in place to assure a $2 \mathrm{~mm}$ thickness of the epoxy resin. The application of the PD connection is easier and quicker. The pre-drilled holes are made with a $90^{\circ}$ angle with the longitudinal axis of the timber element after which the steel connectors are hammered in the holes.

In Figure 3 and Figure 4 is presented a schematic representation of the connections applied in a full-size bridge. The longitudinal spacing will vary depending on the shear stresses acting in the timber-concrete interface and also depending on the level of composite action desired for the cross-section.
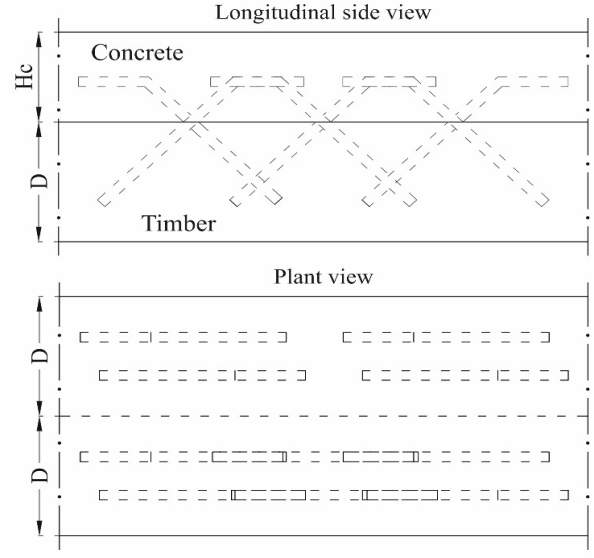

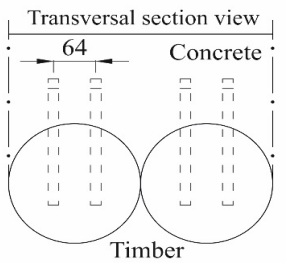

Hc - Concrete slab height

D - Timber log diameter

Figure 3: Schematic representation of the XD connection application in full-size bridge.
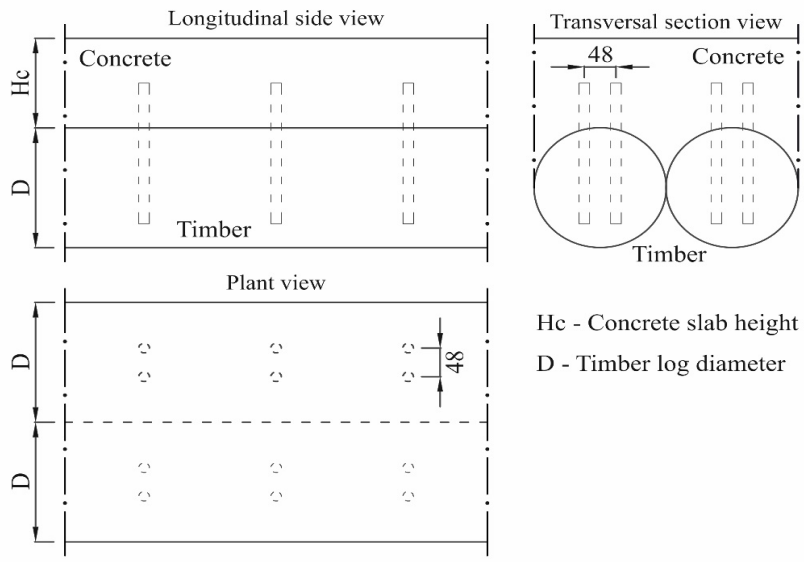

Hc - Concrete slab height D - Timber log diameter

Figure 4: Schematic representation of the PD connection application in full-size bridge.

Maritime pine (Pinus pinaster) was considered due to the good mechanical properties and potential for high-stress structural applications (Martins and Dias 2012, Dias et al. 2014, Morgado et al. 2017). For outdoor applications, where the direct contact with water may occur often, the timber elements may be preservative treated by impregnation, with products based on copper compounds, to prevent the decay and ensure the necessary durability for the structure. 


\section{Experimental procedure}

The static shear tests performed followed the indications of (CEN 1991), which is directed for timber joints made with mechanical fasteners. However, the lack of standardisation for TCC connections led to the use of this standard by the scientific community. The loading procedure was followed accordingly and the value for the estimated maximum load $\left(F_{\text {est }}\right)$, in the first stage, for the first PD specimen, was $100 \mathrm{kN}$, however this value was adjusted because the maximum load $\left(F_{\max }\right)$ obtained in the test deviated more than $20 \%$ from this value, as indicated in the standard. For the XD connection the value of the estimated maximum load was $200 \mathrm{kN}$ for the first specimen and $275 \mathrm{kN}$ for the remaining.

For the cyclic tests in TCC connections the lack of regulations is more evident once there are no stablished procedures or rules for this type of tests. Therefore, based on the procedures found in the relevant literature, a loading procedure was created for the tests of the present study. Firstly, a pre-load was applied and maintained for 10 seconds, after which the cyclic loading was applied in form of a sine wave, with a frequency of $1 \mathrm{~Hz}$. The minimum applied load level $\left(P_{\text {min }}\right)$, for all specimens, was $15 \mathrm{kN}$ corresponding to $10 \% F_{\text {est.cyc }}$. Different maximum load levels $\left(P_{\max }\right)$ were considered for the cyclic tests in order to obtain a wide characterization of the cyclic behaviour of the connection. Therefore, the maximum load levels of $40 \% F_{\text {est.cvc }}, 60 \% F_{\text {est.cyc }}$ and $80 \%$ $F_{\text {est,cyc }}$ were used for the determination of the number of cycles until failure of the connection.

Additionally, load levels of $30 \% F_{\text {est,cyc }}$ and $40 \% F_{\text {est,cyc }}$ were also considered for the evaluation of the influence of cyclic loading in the load carrying capacity and connection stiffness. For this purpose, several specimens were tested under cyclic loading, with a pre-defined number of cycles after which they were tested until failure through static tests. For the assessment of the stiffness, static tests up to the load level of $40 \% F_{\text {est.cyc }}$ were performed at different intervals of the load cycles (Table 2).

During the tests, slip values between the timber and concrete were monitored and recorded. To this end, four displacement transducers of $25 \mathrm{~mm}$ maximum capacity, two per shear plane, were used. Load cells, with maximum capacities of $400 \mathrm{kN}$ and $200 \mathrm{kN}$, were also used to measure and register the applied load. For the calculations, the average slip per shear plane was considered.

\section{RESULTS AND DISCUSSION}

\section{First stage - static tests}

Table 3 presents a summary of the XD connection results, and Figure 5 shows the load-slip curve obtained for these tested specimens. Similarly, the results obtained for the 14 specimens of PD1 series and for the additional 11 specimens of PD2 series, are shown in Table 3. The load-slip curves for each set of specimens are shown in Figure 6 and Figure 7, respectively. The results given for the load carrying capacity are relative to the entire specimen whilst the stiffness values are the average values of both shear planes. For the calculation of stiffness was considered that the applied load was equally resisted by the two connections present in each specimen.

Table 3: Summary of the results for the XD and PD connection - load carrying capacity and stiffness.

\begin{tabular}{|c|c|c|c|}
\hline $\begin{array}{c}\text { Connection } \\
\text { Type }\end{array}$ & & $\left.\mathbf{F}_{\mathbf{m a x}} * \mathbf{k N}\right)$ & $\mathbf{K}_{\mathbf{s}}{ }^{*} \mathbf{( k N / \mathbf { m m } )}$ \\
\hline \multirow{2}{*}{$\begin{array}{c}\text { XD connection } \\
\text { type - 13 } \\
\text { specimens }\end{array}$} & Mean Value & 270,3 & 228,7 \\
\cline { 2 - 4 } & Minimum Value & 242,2 & 168,4 \\
\cline { 2 - 4 } & Maximum Value & 310,3 & 318,9 \\
\cline { 2 - 4 } & CoV (\%) & 7,84 & 20,9 \\
\hline \multirow{3}{*}{$\begin{array}{c}\text { PD1 series - 14 } \\
\text { specimens }\end{array}$} & Mean Value & 127,7 & 35,9 \\
\cline { 2 - 4 } & Maximum Value & 109,7 & 25,6 \\
\cline { 2 - 4 } & CoV (\%) & 151,7 & 52,2 \\
\hline \multirow{3}{*}{$\begin{array}{c}\text { PD2 series - 11 } \\
\text { specimens }\end{array}$} & Mean Value & 9,5 & 20,6 \\
\cline { 2 - 4 } & Minimum Value & 166,8 & 37,1 \\
\cline { 2 - 4 } & Maximum Value & 129,7 & 17,0 \\
\cline { 2 - 4 } & CoV (\%) & 11,0 & 34,8 \\
\hline
\end{tabular}

* - The values of $F_{\max }$ presented are for the entire specimen, while the values of $K_{s}$ are the average between the two shear planes. 


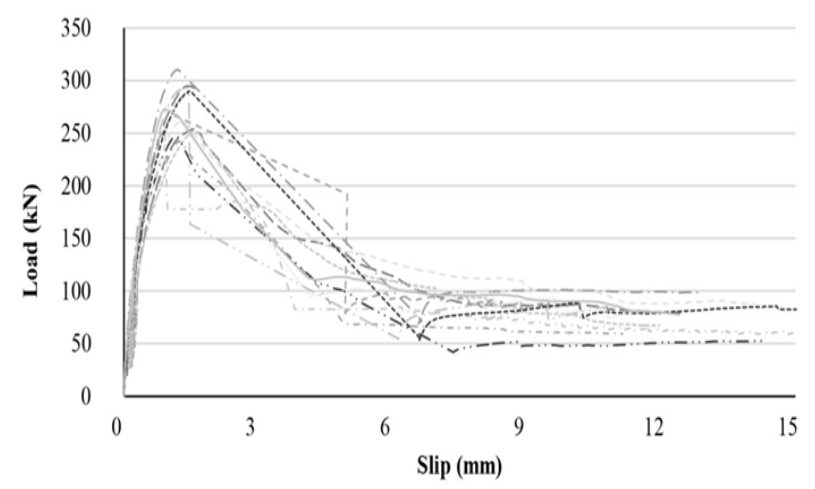

Figure 5: Load-slip curves of XD connection specimens.

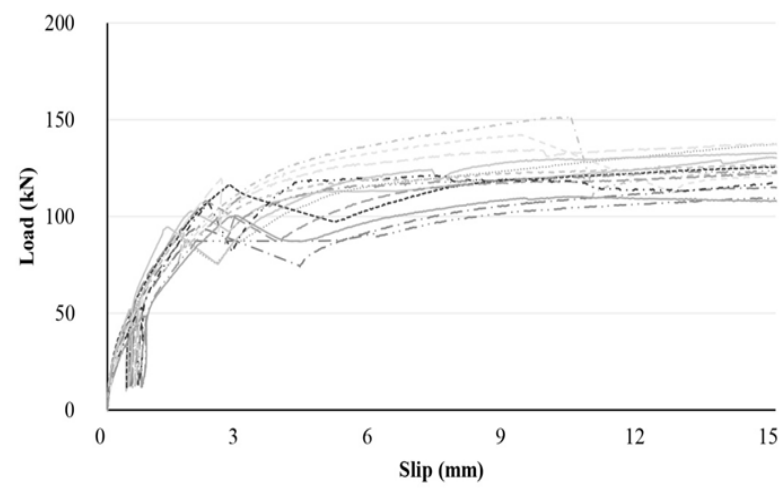

Figure 6: Load-slip curves of PD connection specimens - PD1 series.

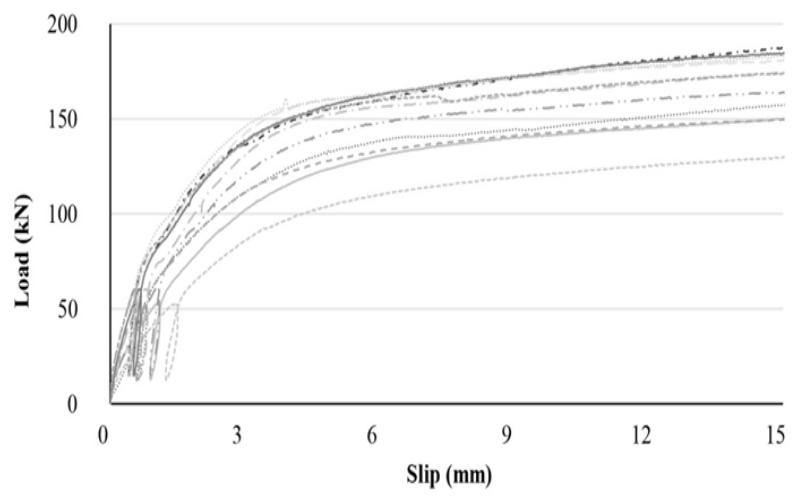

Figure 7: Load-slip curves of PD connection specimens - PD2 series.

The XD connection, as expected, presented higher results, both for the load carrying capacity and stiffness, with mean values of $270,3 \mathrm{kN}$ and $228,7 \mathrm{kN} / \mathrm{mm}$, respectively, which represents increases of $364 \%$ and $501 \%$, respectively, when compared with the results obtained for similar configuration (Molina 2008). Nevertheless, during the tests it was observed that XD connection had a highly fragile behaviour and the failure of the spec- 
imens occurred for lower slip values (less than 1,5 mm) Figure 5. Before the maximum load was reached, the visible failure signs were some cracks in the concrete elements. The predominant failure mode was splitting in the concrete, most likely because it was not used any reinforcement steel in the concrete parts. It was also possible to identify areas with clear signs of embedment in the timber elements caused by the connectors. The epoxy-resin used was found to be suitable for this application once were not found signs of failure neither signs of shear in the resin-timber interface.

The PD connection presented lower values for both the load carrying capacity and stiffness in both PD1 and PD2 series. Mean values of $127,7 \mathrm{kN}$ and $166,8 \mathrm{kN}$ for the maximum load, and 35,9 kN/mm and 37,1 $\mathrm{kN} / \mathrm{mm}$, for the stiffness, respectively for PD1 and PD2 series were obtained.

This type of connection showed a very ductile behaviour in the shear tests. For the majority of the specimens, the test was stopped after the average slip in the timber-concrete, measured in both shear planes, reached $15 \mathrm{~mm}$, as defined in the followed standard. The load carrying capacity of the connection was often the measured load for that slip. For the PD connection was not observed an evidenced failure mode, however, in all of the PD1 series specimens, the concrete part broke in two pieces, due to tension stresses, at the height of shear plane 1. This event is visible in Figure 6, which corresponds to the sudden break point in the applied load, associated with an increase in the slip. After the concrete failure, the load decreased, however the connections keep to resist to the applied load. As mentioned, the concrete failed since no rein for cement steel was used. To prevent this a rein for cement steel mesh was used in the PD2 series specimens. As observed in Figure 7, the incorporation of the rein for cement steel effectively prevented the concrete failure and improved the specimens behaviour, namely its ductility.

\section{Second stage - cyclic tests}

For the second stage of the present study, only one configuration was considered. For the selection of the connection the results of the mechanical properties were taken into account but emphasis was given to the practical an economic aspects. Hence, due to the speed and ease of execution together with the lower costs in the fabrication process, the PD connection was chosen for further testing. Despite the good results for the mechanical properties of the XD connection, during the fabrication of the specimens several difficulties were found, such as the drilling of the holes in the timber elements with an angle of $45^{\circ}$ but especially the application of the epoxy-resin. The presence of large cracks in the timber logs led to the drainage of the epoxy-resin through those cracks, making the gluing process more complex, time-consuming and increased the amount of epoxy-resin used and consequently the related costs. Taking into account the intended application of such system (rural and forest roads with low visibility) the PD connection was considered suitable not only due to the mentioned aspects but also because the availability of technical and human resources in the construction site would not allow the desired and needed quality control for the correct execution of the XD connection type.

The specimens fabricated for the cyclic tests had the reinforcement steel in the concrete members. In the first 9 specimens a pre-defined number of cycles was applied and intermediate static tests for different number of cycles were performed for the evaluation of the connection stiffness (Table 2). When the cyclic loading ended, the specimens were tested to failure in static tests - obtained results are presented in Table 4.

Table 4: Residual load carrying capacity obtained after the application of the pre-defined number of cycles in the PD specimens.

\begin{tabular}{|c|c|c|c|}
\hline Specimen & $\begin{array}{c}\text { Load } \\
\text { Level }\end{array}$ & $\begin{array}{c}\text { Number } \\
\text { of Cycles }\end{array}$ & $\begin{array}{c}\mathbf{F}_{\max } \\
(\mathbf{k N})\end{array}$ \\
\hline PD_32 & $30 \% \mathrm{~F}_{\text {est }}$ & 10000 & 153,2 \\
\hline PD_31 & $30 \% \mathrm{~F}_{\text {est }}$ & 100000 & 166,2 \\
\hline PD_33 & $30 \% \mathrm{~F}_{\text {est }}$ & 100000 & 178,3 \\
\hline PD_47 & $40 \% \mathrm{~F}_{\text {est }}$ & 1000 & 172,6 \\
\hline PD_49 & $40 \% \mathrm{~F}_{\text {est }}$ & 1000 & 195,5 \\
\hline PD_43 & $40 \% \mathrm{~F}_{\text {est }}$ & 10000 & 188,4 \\
\hline PD_48 & $40 \% \mathrm{~F}_{\text {est }}$ & 10000 & 188,2 \\
\hline PD_42 & $40 \% \mathrm{~F}_{\text {est }}$ & 100000 & 200,7 \\
\hline PD_50 & $40 \% \mathrm{~F}_{\text {est }}$ & 100000 & 163,8 \\
\hline
\end{tabular}


The mean value for the initial stiffness $\left(K_{\text {s,ini }}\right)$, before the beginning of the cyclic tests, was $37,4 \mathrm{kN} / \mathrm{mm}$. In the end of the cyclic tests it was observed that the stiffness of the connections increased -mean value for the final stiffness $\left(K_{s, f i n}\right)$ was $55,5 \mathrm{kN} / \mathrm{mm}$, corresponding to an average increase of $48,5 \%$, relative to the initial stiffness. The mean value for the load carrying capacity was $178,5 \mathrm{kN}$.

Regarding the general behaviour of the connection stiffness, in the specimens tested until 100000 cycles, it was possible to observe a general trend - in all specimens, after the first static test and the initial cycles, the stiffness of the connection increased and remained in an approximate constant level, with a slight decrease before the failure test, as shown in Figure 8. For the remaining specimens, tested up to 1000 and 10000 cycles, Figure 9, this behaviour was also observed even if not so noticeably. The increase in the stiffness is believed to be related with the stiffening of the timber in the contact area with the connectors, after the first loading. This stiffening of the timber also resulted in an increase in the slip of the connection, as exemplified for the PD_50 specimen, in Figure 10.

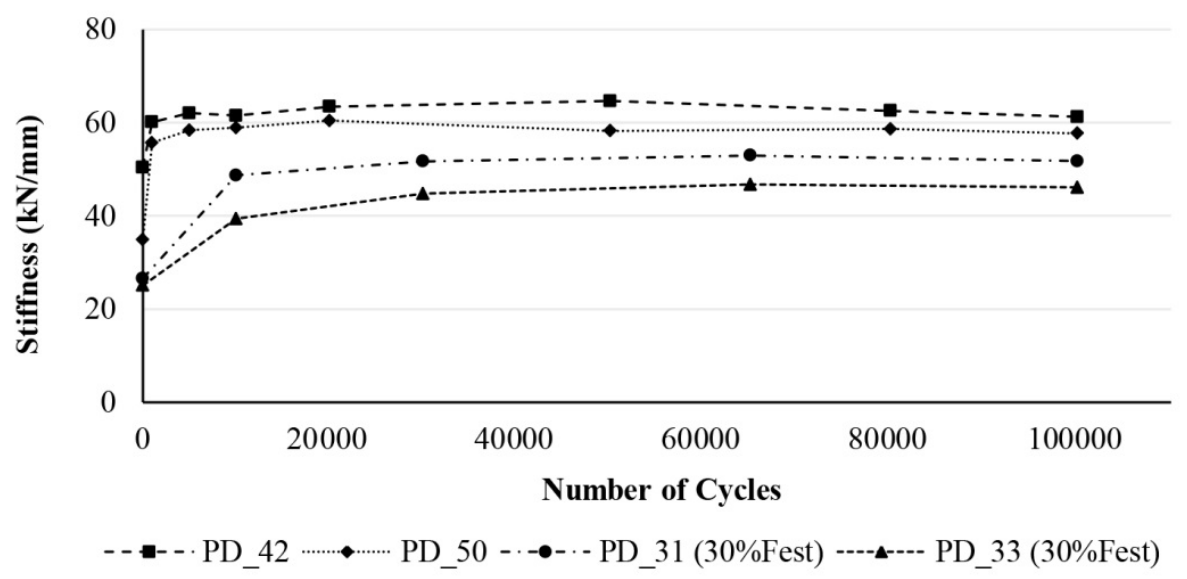

Figure 8: Stiffness behaviour during the cyclic loading, for specimens tested until 100000 cycles.

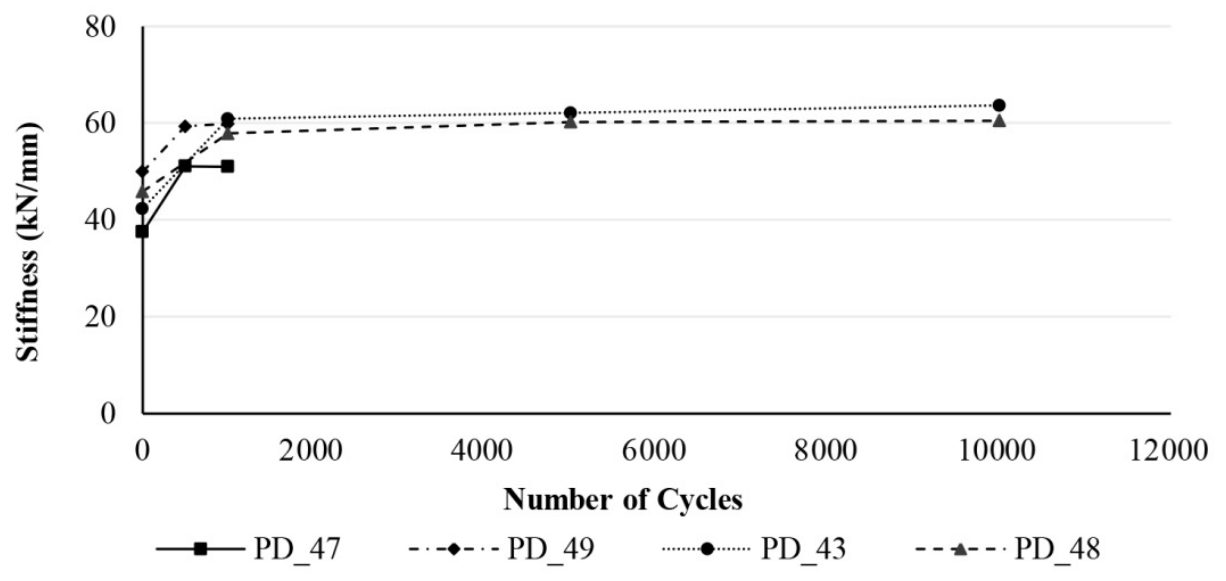

Figure 9: Stiffness behaviour during the cyclic loading, for specimens tested until 1000 and 10000 cycles. 


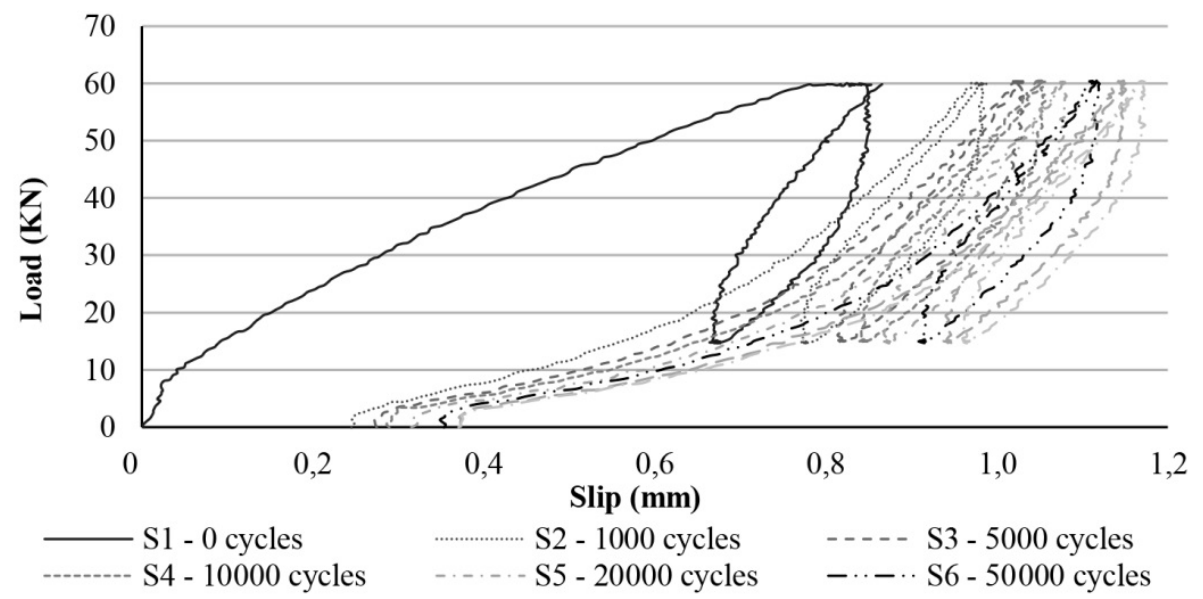

Figure 10: Evolution of load-slip curves for the PD_50 specimens.

In order to extend the assessment of the cyclic loading influence in the connection stiffness, a second set of cyclic tests was performed. A total of 11 specimens were tested until failure (Table 2). The exception was the specimen where the maximum load level of $20 \% F_{\text {est.cyc }}$ was adopted, that reached more than 7 million load cycles and no failure signs were detected.

The total number of cycles until failure are shown in Table 5. In all specimens, the failure mode observed was controlled by shear in the connectors, but usually only in one of the shear planes (shear plane 2 - as defined in Figure 2), after which the test was stopped. Similarly to what was observed in the static tests, embedment was also found in the timber members.

Static tests to determine the stiffness of the connection were also performed in order to monitor its behaviour during the cyclic tests and until failure occurred. Whenever possible, the cyclic tests were run continuously and, usually, one static test per day was performed. However, since the specimens tested with the load levels of $60 \% F_{\text {est,cyc }}$ and $80 \% F_{\text {est.cyc }}$ failed with less than 100000 cycles and 21000 cycles, respectively, only a few number of static tests for stiffness determination were performed. The specimens tested with the load level of $40 \% F_{\text {est, }, v c}$ allowed a reasonable evaluation of the respective connection stiffness until failure.

Table 5: Number of cycles until failure of the specimens.

\begin{tabular}{|c|c|c|c|c|}
\hline Specimen & $\mathbf{P}_{\min }{ }^{*}$ & $\mathbf{P}_{\max }{ }^{*}$ & $\mathbf{R}=\mathbf{P}_{\min } / \mathbf{P}_{\max }$ & Number of cycles \\
\hline PD_16 & $10 \%=15 \mathrm{kN}$ & $40 \%=60 \mathrm{kN}$ & 0,25 & 580692 \\
\hline PD_18 & $10 \%=15 \mathrm{kN}$ & $40 \%=60 \mathrm{kN}$ & 0,25 & 1131454 \\
\hline PD_19 & $10 \%=15 \mathrm{kN}$ & $40 \%=60 \mathrm{kN}$ & 0,25 & 336050 \\
\hline PD_22 & $10 \%=15 \mathrm{kN}$ & $40 \%=60 \mathrm{kN}$ & 0,25 & 484701 \\
\hline PD_21 & $10 \%=15 \mathrm{kN}$ & $60 \%=90 \mathrm{kN}$ & 0,17 & 85517 \\
\hline PD_23 & $10 \%=15 \mathrm{kN}$ & $60 \%=90 \mathrm{kN}$ & 0,17 & 92976 \\
\hline PD_24 & $10 \%=15 \mathrm{kN}$ & $60 \%=90 \mathrm{kN}$ & 0,17 & 92755 \\
\hline PD_26 & $10 \%=15 \mathrm{kN}$ & $80 \%=120 \mathrm{kN}$ & 0,13 & 20893 \\
\hline PD_27 & $10 \%=15 \mathrm{kN}$ & $80 \%=120 \mathrm{kN}$ & 0,13 & 15254 \\
\hline PD_34 & $10 \%=15 \mathrm{kN}$ & $80 \%=120 \mathrm{kN}$ & 0,13 & 13274 \\
\hline
\end{tabular}

* The estimated maximum load for the cyclic tests $\left(F_{\text {est, cyc }}\right)$ was $150 \mathrm{kN}$ for all specimens. 
Figure 11 shows the evolution of the connection stiffness for the specimens tested with the load level of $40 \% F_{\text {est.cvc }}$. The behaviour was similar to that observed in the first set of cyclic tests - Figure 8. In general, after the first applied load cycles the stiffness value increased and remained approximately constant, after which it started to decrease, before the failure. However, an important observation is that none of the specimens had a final stiffness value lower than the initial stiffness.

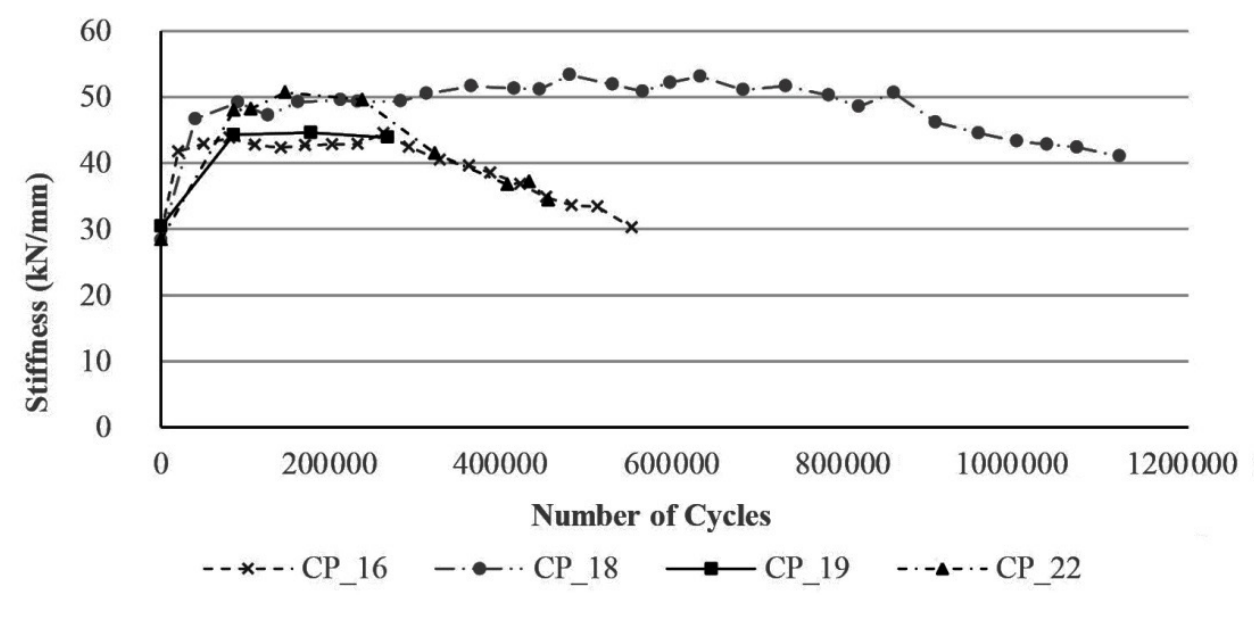

Figure 11: Stiffness behaviour for the specimens cyclic tested until failure - load level of $40 \% F_{\text {est,cyc }}$.

The values obtained for the connection stiffness when the load levels of $60 \% F_{\text {est.cyc }}$ and $80 \% F_{\text {est.cyc }}$ were applied, are presented in Table 6 . For the specimens tested with the load level of $60 \%{ }^{\text {est.cyc }} F_{\text {est.cyc }}$, after the first 100 cycles an average decrease of $9,6 \%$ was observed in terms of connection stiffness. In the last static test before the failure, the average reduction was $41,1 \%$ relative to the initial stiffness. For the specimens tested with the load level of $80 \% F_{\text {est.cyc }}$, only one static test was performed after the initial stiffness test and before the failure. After the first 100 cycles, the connection stiffness decreased, in average, $37 \%$ relative to the initial stiffness.

According to the obtained results, $60 \% F_{\text {est.ccc }}$ and $80 \% F_{\text {est.cyc }}$ load levels were more severe to the connection, contrary to what was observed for the $40 \% F_{\text {est.cyc }}$ load level - after the initial cycles the stiffness was affected and decreased significantly, with particular emphasis for the specimens tested with the higher load level $\left(80 \% F_{\text {estcyc }}\right)$. The number of cycles until failure of the specimens was also significantly influenced by the different load levels, being observed an average reduction of $85,7 \%$ and $97,4 \%$ in the number of cycles until failure of the $60 \% F_{\text {est,cyc }}$ specimens and $80 \% F_{\text {est,cyc }}$ specimens, relatively to the $40 \% F_{\text {est.cyc }}$ specimens. Despite of that, a good relation $\left(\mathrm{R}^{2}=0,96\right)$ between the load amplitude of the cyclic tests and the number of cycles until failure was found, as shown in Figure 12, indicating that the PD connection tested in this study presents a consistent mechanical behaviour, for the different load amplitude levels. 
Table 6: Evolution of the connection stiffness during cyclic tests for the specimens with the load level of $60 \% F_{e s t}$ and $80 \% F_{e s t}$

\begin{tabular}{|c|c|c|c|c|}
\hline Specimen & $\begin{array}{l}\text { Load } \\
\text { Level }\end{array}$ & $\begin{array}{l}\text { Number of } \\
\text { Cycles }\end{array}$ & $\mathrm{K}_{\mathrm{s}}(\mathrm{kN} / \mathrm{mm})$ & $\begin{array}{c}\text { Stiffness } \\
\text { Variation } \\
(\%)\end{array}$ \\
\hline \multirow{4}{*}{ PD_21 } & \multirow{4}{*}{$\begin{array}{c}60 \% \\
F_{\text {est }}\end{array}$} & 0 & 36,4 & - \\
\hline & & 100 & 32,3 & $-11,5 \%$ \\
\hline & & 80100 & 23,0 & $-36,9 \%$ \\
\hline & & 85517 & Failure & - \\
\hline \multirow{4}{*}{ PD_23 } & \multirow{4}{*}{$\begin{array}{l}60 \% \\
\mathrm{~F}_{\text {est }}\end{array}$} & 0 & 38,0 & - \\
\hline & & 100 & 37,9 & $-0,3 \%$ \\
\hline & & 80100 & 24,1 & $-36,7 \%$ \\
\hline & & 92976 & Failure & - \\
\hline \multirow{4}{*}{ PD_24 } & \multirow{4}{*}{$\begin{array}{c}60 \% \\
\mathrm{~F}_{\text {est }}\end{array}$} & 0 & 45,5 & - \\
\hline & & 100 & 37,8 & $-17,0 \%$ \\
\hline & & 80100 & 22,9 & $-49,6 \%$ \\
\hline & & 92755 & Failure & - \\
\hline \multirow{3}{*}{ PD_26 } & \multirow{3}{*}{$\begin{array}{c}80 \% \\
\mathrm{~F}_{\text {est }}\end{array}$} & 0 & 31,8 & - \\
\hline & & 100 & 18,9 & $-40,6 \%$ \\
\hline & & 20893 & Failure & - \\
\hline \multirow{3}{*}{ PD_27 } & \multirow{3}{*}{$\begin{array}{c}80 \% \\
\mathrm{~F}_{\text {est }}\end{array}$} & 0 & 36,3 & - \\
\hline & & 100 & 22,1 & $-39,1 \%$ \\
\hline & & 15254 & Failure & - \\
\hline \multirow{3}{*}{ PD_34 } & \multirow{3}{*}{$\begin{array}{c}80 \% \\
\mathrm{~F}_{\text {est }}\end{array}$} & 0 & 26,8 & - \\
\hline & & 100 & 18,4 & $-31,2 \%$ \\
\hline & & 13274 & Failure & - \\
\hline
\end{tabular}

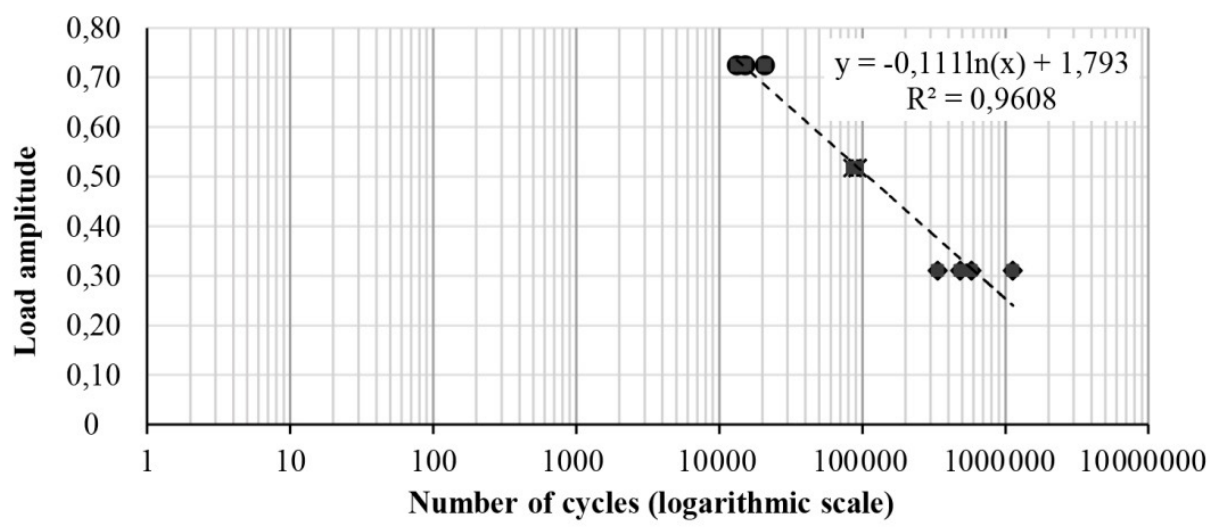

- $80 \%$ Fest,cyc $\quad * 60 \%$ Fest,cyc $\bullet 40 \%$ Fest,cyc

Figure 12: Load amplitude $v s$ number of cycles to failure.

\section{CONCLUSIONS}

The mechanical properties of two types of connections intended for application in TCC bridge decks, using round wood elements, were determined through static tests. The XD connection type showed a very good performance, but for the intended application, the PD connection configuration was chosen for further testing, based on practical and economical aspects. 
For the complete characterization of this type of connection cyclic tests were also performed. After 10000 cycles, an average increase of $80,6 \%$ was observed in the connection stiffness for the $30 \% F_{\text {est,cyc }}$ tested specimens, and of $34,1 \%$ after 1000 for the $40 \% F_{\text {est,cyc }}$ tested specimens.

Furthermore, additional specimens were tested with cyclic loads until failure occurred caused by fatigue, and the total number of cycles until failure was recorded. It was concluded that the different load levels applied had influence in both mechanical properties of the PD connection, but mainly in the stiffness. For the higher load levels applied $\left(60 \%\right.$ and $\left.80 \% F_{\text {est. crc }}\right)$, the connection stiffness was severely affected and, before the failure, the measured stiffness was lower than the initial stiffness. For the $40 \% F_{\text {est.cvc }}$ load level, the behaviour was different - stiffness increased to an approximate constant value (at approximately 100000 cycles), and decreased constantly, in mostly all specimens.

A high relation was found $\left(\mathrm{R}^{2}=0,96\right)$ between the load amplitude and the number of cycles until failure. Thus, indicating the possibility to use the results of this study for comparison with the expected number of load cycles in the lifetime of a TCC bridge, based on the amplitude of the shear forces acting in the connection and the expected traffic volume in the bridge.

\section{ACKNOWLEDGEMENTS}

This work was partly financed by FEDER funds through the Competitiveness Factors Operational Program - COMPETE and by national funds through FCT - Foundation for Science and Technology within the scope of the project POCI-01-0145-FEDER-007633.

The authors also gratefully acknowledge the European Union Fund FEDER for financial support provided through the operation CENTRO-01-0145-FEDER-000006 (SUSpENsE Sustainable built Environment under Natural Hazards and Extreme Events) and through the research project QREN 30224 (Eco-Tabuleiro).

\section{REFERENCES}

Aldi, P.; Kuhlmann, U. 2010. Fatigue strength of timber-concrete composite bridges: determination of a S-N line for the grooved connection and the "X-connector". Proceedings of the 11th World Conference on Timber Engineering.Trento, Italy.

Calil, J. 2006. Manual de Projeto e Construção de Pontes de Madeira. São Carlos, Brazil, LaMEM - Laboratório de Madeiras e de Estruturas de Madeira.

Calil, J.; Pigozzo, J.C.; Lahr, F.A.R. 2004.The first composed log-concrete deck bridge in Brazil. World Conference on Timber Engineering.Helsinki, Finland.

Comité Européen de Normalisation. CEN. 1991. Timber Structures - Joints made with mechanical fasteners - General principles for the determination of strength and deformation caracteristics. CEN. 1991. EN 26891. Brussels: Comité Européen de Normalisation.

Comité Européen de Normalisation. CEN. 2003. Eurocode 1 - Actions on structures. Part 2: Traffic loads on bridges. EN 1991-2. Brussels: Comité Européen de Normalisation.

Comité Européen de Normalisation. 2004a. Eurocode 2 - Design of concrete structures. Part 1-1: General rules and rules for buildings. EN 1992-1-1. Brussels: Comité Européen de Normalization.

Comité Européen de Normalisation. CEN. 2004b. Eurocode 5 - Design of Timber Structures. Part 2: Bridges. EN 1995-2. Brussels, Belgium: Comité Européen de Normalisation.

CSA .2016. S6-14: Canadian Highway Bridge Design Code. Ontario, Canada, CSA Group: 875.

Dias, A.; Skinner, J.; Crews, K.; Tannert, T. 2016. Timber-concrete-composites increasing the use of timber in construction. European Journal of Wood and Wood Products74(3): 443-451. https://doi.org/10.1007/ s00107-015-0975-0.

Dias, A.M.P.G.; Machado, J.S.; Santos, P. 2014. Uso de produtos de madeira de alto desempenho em aplicações estruturais. JPEE 2014 - 5as Jornadas Portuguesas de Engenharia de Estruturas, Lisboa, Portugal.

Dias, A.M.P.G.; Martins, A.R.D.; Simoes, L.M.C.; Providencia, P.M.; Andrade, A. A.M. 2015. Statistical analysis of timber-concrete connections - Mechanical properties. Computers \& Structures 155: 67-84. 
https://doi.org/10.1016/j.compstruc.2015.02.036.

Döhrer, A.; Rautenstrauch, K. 2006. Connectors for timber-concrete composite-bridges. 39th Meeting of Working Commission W18-Timber Structures, International Council for Research and Innovation in Building and Construction (CIB), Florence, Italy.

Gang Hu, W.; Yuan Guan, H. 2019. Study on compressive stress relaxation behavior of beech based on the finite element method. Maderas. Ciencia y Tecnología 21(1): 15-24. https://doi.org/10.4067/S0718$221 \times 2019005000102$.

Hermoso, E.; Fernández-Golfín, J.; Conde, M.; Troya, M.T.; Mateo, R.; Cabrero, J. 2015. Caracterización de la Madera Aserrada de Pinus radiata modificada térmicamente. Maderas. Ciencia y Tecnología 17(3): 493-504. https://doi.org/10.4067/S0718-221X2015005000044.

Knapic, S.; Santos, J.; Santos, J.; Pereira, H. 2018. Natural durability assessment of thermo-modified young wood of Eucalyptus. Maderas. Ciencia y Tecnología 20(3): 489-498. https://doi.org/10.4067/S0718221X2018005031801.

Mäkipuro, R.;Tommola, J.; Salokangas, L.; Jutila, A. 1996. Wood-Concrete Composite Bridges. Nordic Timber Bridge Project. Stockholm, Sweden, Nordic Timber Council.

Marques, A.F.S.; Martins, C.E.J.; Dias, A.M.P.G.; Costa, R.J.T.; Morgado, T.F. M. 2016. Assessment of Reuse Potential of Maritime Pine Utility Poles for Structural Applications after Removal from Service. BioResources 11(4): 9340-9349.

Martins, C.; Dias, A. 2012. Bending Strength and Stiffness of Portuguese Maritime Pine Utility Poles. Forest Products Journal 62(2): 114-120.

Martins, C.; Dias, A.M.P.G.; Costa, R.; Santos, P. 2016. Environmentally friendly high performance timber-concrete panel. Construction and Building Materials 102 (Part 2): 1060-1069. https://doi.org/10.1016/j. conbuildmat.2015.07.194.

Martins, C.E.J.; Dias, A.M.P.G.; Marques, A.F.S.; Dias, A.M.A. 2017. Non-Destructive Methodologies for Assessment of the Mechanical Properties of New Utility Poles. BioResources 12(2): 2269-2283. https://doi. org/10.15376/biores.12.2.2269-2283.

Morgado, T.F.M.; Dias, A.M.P.G.; Machado, J.S.; Negrão, J.H.; Marques, A.F.S. 2017. Grading of Portuguese Maritime Pine Small-Diameter Round wood. Journal of Materials in Civil Engineering 29(2): 1-7.

Molina, J.C. 2008. Análise do comportamento dinâmico da ligação formada por barras de aço coladas para tabuleiros mistos de madeira e concreto para pontes. Ph.D. Thesis, University of São Paulo, São Paulo, Brasil.

Rautenstrauch, K.; Mueller, J.; Simon, A. 2010.The first timber-concrete composite road bridge in Germany. World Conference on Timber Engineering, Trento, Italy.

Rodrigues, J.; Providência, P.; Dias, A. 2010. Use of composite timber-concrete bridges solutions in Portugal. International Conference on Timber Bridges (ICTB 2010), Norway.

Rodrigues, J.N.; Dias, A.M.P.G.; Providência, P. 2013. Timber-Concrete Composite Bridges: State-ofthe-Art Review. BioResources 8(4): 6630-6649.

RTA. 2008. Timber Bridge Manual. Timber concrete composite bridges, RTA - Roads and Traffic Authority of NSW.

Sebastian, W.M.; Bell, O.G.A.; Martins, C.; Dias, A.M.P.G. 2017. Experimental evidence for effective flexural-only stiffnesses to account for nonlinear flexural-slip behaviour of timber-concrete composite sections.Construction and Building Materials 149: 481-496. https://doi.org/10.1016/j.conbuildmat.2017.04.082.

Soriano, J.; Mascia, N.T. 2009. Timber-concrete composite structures: a rational technique for bridges of vicinal roads. Ciencia Rural 39(4): 1260-1269.

Tommola, J.; Salokangas, L.; Jutila, A. 1999. Tests on shear connectors. Nordic Timber Bridge Project. Stockholm, Sweden, Nordic Timber Council. 